\title{
A NORMA FUNDAMENTAL HIPOTÉTICA DE KELSEN E ANTINOMIA EM RELAÇÃO ÀS CARTAS CONSTITUCIONAIS DEMOCRÁTICAS, COM DESTAQUE À CARTA DEMOCRÁTICA BRASILEIRA DE 1988
}

\author{
Paulo Henrique Martins* \\ Dirceu Pereira Siqueira**
}

\begin{abstract}
RESUMO: Objetiva-se, neste trabalho, demonstrar que a teoria de Kelsen, quanto à compreensão de norma fundamental hipotética, destoa com a Constituição Federal de 1988, porque não se pode mais combatibilizar o "elemento revolucionário" como única forma de se buscar o fundamento de validade da norma constitucional escrita. Enfatiza-se os conceitos de direito, ordenamento, supremacia constitucional e a atual fase do constitucionalismo contemporâneo e os valores humanos conquistados a partir da Segunda Guerra Mundial, valores que esbarram em antinomia, por exemplo, se comparados com o parâmetro de norma fundamental hipotética brasileira, que decorreu do Golpe Militar de 1964 e o AI 05.
\end{abstract}

Palavras-Chaves: Norma fundamental hipotética; Revolução; Antinomia; Constituição Federal de 1988.

\section{THE KELSEN'S HYPOTHETICAL FUNDAMENTAL NORM AND ANTINOMY IN RELATION TO THE DEMOCRATIC CONSTITUTIONAL CHARTS, WITH FEATURE FOR THE BRAZILIAN DEMOCRATIC CHARTER OF 1988}

\begin{abstract}
The purpose of this research is to demonstrate that Kelsen's theory, about of a hypothetical fundamental norm, disagrees with the Federal Constitution of 1988, because it's no longer possible to combat the "revolutionary element" as the only way to find validity of the written constitutional norm. It emphasizes the concepts of law, order, constitutional supremacy and the current phase of contemporary constitutionalism and the human values conquered after World War II, values that run counter to antinomy, for example, when compared with the Brazilian standard hypothetical norm, Which resulted from the Military Coup of 1964 and the "AI 05".
\end{abstract}

Keywords: Hypothetical fundamental norm. Revolution. Antinomy. Federal Constitution of 1988.

\footnotetext{
* Mestre em Direito pelo Centro Universitário de Maringá - UNICESUMAR (2017). Possui pós-graduação em Direito Tributário pelo Centro Universitário Leonardo Da Vinci (2015). Possui pós-graduação em Direito do Estado pela UNIDERP (2011). Possui graduação em Direito pelo Centro Universitário Eurípides de Marília (2008).

${ }^{* *}$ Pós-doutor em Direito pela Faculdade de Direito da Universidade de Coimbra (Portugal). Doutor e Mestre em Direito Constitucional pelo Centro de Pós-Graduação da ITE/Bauru. Professor e Advogado. Endereço eletrônico: dpsiqueira@uol.com.br.
} 


\section{INTRODUÇÃO}

Com o presente artigo, abrir-se-á discussão de uns dos temas mais conhecidos da obra Hans Kelsen, qual seja, a norma fundamental hipotética e seu sistema hierarquizado de leis. Pretende-se conscientizar o leitor a respeito do problema que o purismo da obra do aludido autor pode trazer, quando comparado à realidade constitucional contemporânea, mormente quanto à Constituição Federal brasileira de 1988.

Cumpre mencionar que o motivo que levou a escolher referido tema foi a importância da teoria de Kelsen na compreensão da estrutura de leis e o sistema jurídico. Os avanços dessa teoria para o direito são inegáveis e, claro, dignas de compreensão e discussão.

O estudo inicia-se traçando um conceito de Direito, já dizendo que possui conceito que se amplia com o passar dos anos. Uma concepção atual deve ser mais abarcadora possível, tudo em vista à complexidade que se encontra a sociedade na atualidade. Desse modo, o que dá cor e conteúdo ao Direito são as normas jurídicas.

As normas jurídicas, o sistema jurídico como um todo, são estruturados de uma maneira ordenada, de forma que o sistema se mantenha como um todo coeso e unitário. Assim, a hierarquia de leis, a forma piramidal de se conceber as normas jurídicas, possui uma norma mãe, ou norma ápice, que é a constituição nacional.

Kelsen, assim como a maioria dos positivas, busca fundamento de validade de uma lei sobre a outra, subindo em hierarquia até alcançar a lei de mais alto grau do ordenamento. Em sua obra Teoria Pura do Direito, o ilustre Mestre de Viena concorda que a lei primeira de um ordenamento é a constituição nacional. Para fechar sua teoria e evitar uma regressão ao infinito de leis (na tentativa de buscar a primeira lei escrita - ou primeiro texto do qual decorreram os demais), justifica que uma constituição nacional não busca fundamento em outra lei escrita que já existiu, mas sim em uma norma fundamental hipotética.

Essa norma fundamental hipotética, na concepção de aludido autor, é fruto de uma construção histórica ocasionada por meio de uma revolução. Afirma que tudo o que vem de uma Assembleia Nacional Constituinte não pode ser considerado fundamento para a constituição nacional, mas sim aquilo que decorreu de uma revolução, da quebra da ordem anterior, é que seria fundamento de validade para a carta constitucional escrita elaborada posteriormente ao aludido evento.

A partir daí são tecidos comentários a respeito da evolução do fenômeno constitucional, o princípio da supremacia da constituição no sistema de leis e como os princípios 


\section{A NORMA FUNDAMENTAL HIPOTÉTICA DE KELSEN E ANTINOMIA EM RELAÇÃO ÀS CARTAS CONSTITUCIONAIS DEMOCRÁTICAS, COM DESTAQUE À CARTA DEMOCRÁTICA \\ BRASILEIRA DE 1988}

constitucionais, a conquista de direitos individuais e sociais pelo homem, têm um aspecto de extrema importância em relação ao constituinte originário.

Dentro de um sistema de leis, a supremacia da constituição é medida que se impõe para manter a coesão, a ordem, a estabilidade do sistema, tudo em decorrência da hierarquia de leis. As cartas constitucionais da atualidade, com receio de que regimes autoritários se instaurassem novamente, criaram uma série de mecanismos para evitar que o homem fosse subjulgado, em prol de interesses do poder político.

A doutrina de Luís Roberto Barroso arremata ao expor que uma vez a sociedade consiga angariar direitos em frente ao Estado, esses direitos não podem ser suprimidos nem mesmo por nova ordem constitucional.

Com base nesses comentários, chega-se à indagação contida no presente artigo que seria a existência de conflito real de normas envolvendo a constituição nacional e o conceito de norma fundamental hipotética, pela concepção de Hans Kelsen, comparado com a realidade brasileira.

Pela concepção de norma fundamental de aludido autor, o Brasil teria como paradigma histórico o Ato Institucional número 05, fruto de uma revolução militar e imposição do regime ditatorial no país. Só que, no entanto, a Carta Constitucional de 1988 é o extremo oposto do que pregava o regime militar.

Assim, o presente estudo vai tentar responder pela teoria de Kelsen, mais especificamente a respeito da norma fundamental hipotética e se essa antinomia é efetivamente real ou não. No presente artigo, mostrar-se-á que a antinomia é real. Partindo dessa afirmativa, teria os princípios de solução de conflito de normas o condão de solucionar referida problemática? Conforme se demonstrará, a prevalência dos princípios voltado à proteção da pessoa humana é regra que deve se impor de maneira inexorável pelo cientista do Direito.

A proposta aqui não é negar a teoria kelseniana ou muito menos oferecer propostas de reformas, mas sim indagar a respeito da atual situação que o Direito passa no mundo como um todo, da necessidade da busca de valores éticos e morais, vinculados aos direitos humanos e a prioridade da pessoa humana, diante da falência do positivismo, ou seja, necessário se faz buscar soluções mais densificadoras e humanas em relação às normas constitucionais, e de seu próprio parâmetro (norma fundamental hipotética), justamente quando elas entram em conflito.

Para isso, utilizar-se-á de metodologia baseada em pesquisa qualitativa, tecida com base doutrinária (nacional e internacional) e jurisprudencial (especialmente no cenário 
nacional), abordando-se o tema pelo método hipotético-dedutivo, de cunho descritivo e analítico.

Em virtude da complexidade e amplitude do tema, não constitui objetivo do presente trabalho a análise da teoria de Kelsen em todos os ramos do Direito, mas sim no foco da teoria geral do Direito. Muito embora outros ramos constituam pontos relevantes referentes ao tema, não serão abordados dada a extensão de cada um deles.

\section{O CONCEITO DE DIREITO}

A visão do Direito, com o passar dos anos, acaba ganhando uma conotação integradora, conotação que quer acolher o maior número de situações e informações possíveis, que só são suportadas porque nunca se viu a humanidade avançando tanto no campo do saber.

Uma sociedade complexa, portanto, exige que conceitos mais singelos sejam substituídos por conceitos mais complexos, ou que tentem abarcar uma definição completa de Direito.

Se, de um conceito clássico de Direito (que vigorou entre os gregos e romanos e se estendeu até a Idade Média) a conceber o Direito como um conjunto de normas garantidas por uma determinada autoridade (VENOSA, 2009, p. 08), para se ter o bem comum; passa-se para conceitos legalistas de Direito, sociológicos de Direito e culturalistas de Direito (MENDES, 1990, p. 36-40).

Os autores que defendem um conceito puramente legalista de Direito apareceram no contexto do advento dos Estados modernos (com a consequente noção de soberania dos Estados com o delineamento de fronteiras nacionais). Com o código de Napoleão de 1804 e o aparecimento da escola exegética tentou-se reduzir o Direito apenas como sendo um fenômeno da codificação. O Direito seria apenas o que estava contido nos códigos (AMARAL JÚNIOR, APUD COSTA, 2002, p. 67).

Todavia, em contraponto, aqueles que adotam um conceito social ou sociológico de Direito, tendo como o expoente, dentre outros, Auguste Comte, trataram por definir Direito como um fenômeno social. Muitos juristas, como Luís Fernando Coelho, propuseram-se a reduzir a experiência jurídica a meras circunstâncias sociais. Assim, para esses juristas, a ciência jurídica é pura observação dos fatos sociais (COELHO, 2003, p. 118).

Pelo conceito culturalista ou integral de Direito se afirma que "o conceito integral do direito vai procurar sintetizar, num nível amplo de apreciação cultural e dialética, os caracteres 


\section{A NORMA FUNDAMENTAL HIPOTÉTICA DE KELSEN E ANTINOMIA EM RELAÇÃO ÀS CARTAS CONSTITUCIONAIS DEMOCRÁTICAS, COM DESTAQUE À CARTA DEMOCRÁTICA \\ BRASILEIRA DE 1988}

básicos que a complexidade da experiência jurídica deve conter” (MENDES, 1990, p. 40). Tais caracteres básicos seriam o tridimensionalismo, o pluralismo e realismo (temas esses que não são objeto de estudo para os fins propostos neste artigo).

Luís Fernando Coelho trata essas evoluções conceituais da compreensão do Direito, dentro da visão crítica, como sendo respostas necessárias dentro do campo da hermenêutica jurídica, contra os exageros das escolas dogmáticas do século XIX, reinterpretando o próprio papel do operador jurídico.

O tridimensionalismo, criação de Miguel Reale, decorre da própria natureza do direito, porque a compreensão da experiência jurídica é de uma estrutura de normas que ordena determinados atos, segundo valores numa qualificação de tipológica de comportamentos futuros, ligados a determinadas consequências. Para o aludido autor, o pluralismo jurídico admite, no bojo das escolas sociológicas, que o direito estatal busque atingir o "direito efetivo", ou seja, aquele brota espontaneamente das comunidades. Já o realismo teria uma visão mais prosaica do direito, como não sendo leis, nem precedentes, mas sim o direito é o que os tribunais decidem (COELHO, 2003, p. 294/306).

Mas é no conceito purista de Direito de Kelsen que se vão tecer maiores considerações no decorrer deste trabalho. O Mestre de Viena, segundo Antonio Celso Mendes, queria objetivamente retirar do Direito tudo o que não era estritamente jurídico. Não conseguia entender o Direito como ciência se não houvesse conceitos próprios e que não dependessem de outras ciências para receber conteúdo ou dar significação:

Hans Kelsen entendeu necessário purificar o conceito de direito, livrando-o dos
condicionamentos naturais, psíquicos, sociais ou éticos. Era necessário criar um
conceito de direito abstrato, sustentável por si mesmo (a priori), imune às ideologias,
cientificamente objetivo. Tal se deu com o entendimento de que o direito é a norma
jurídica tomada em seu aspecto lógico, cujo dever-ser explica a sua coerência
(MENDES, 1990, p. 40).

Não adianta nada conceber um Direito puro, em essência, se não houvesse mecanismos próprios de aplicação dessa normatividade na sociedade; ou mesmo, não se teria Direito caso não houvesse leis ou normas jurídicas que o dessem cor e conteúdo.

O Estado, o organismo estatal, vai estruturar o Direito, fornecendo agentes que irão impor a aplicação de leis, sancionar quem descumpra a ordem imposta, tudo para garantir o funcionamento de todo o sistema (MACHADO SEGUNDO, 2010, p. 09).

Assim, arrisca-se aqui conceituar Direito como o conjunto de normas jurídicas, impostas pelo organismo estatal a todos em sociedade, trazendo em seu conteúdo ações ou 
omissões valiosas e que, uma vez descumpridas, gerarão sanção a ser aplicada por instituições legitimamente e legalmente criadas para esse fim.

\section{A ESTRUTURA DAS NORMAS JURÍDICAS NO SISTEMA NORMATIVO}

Normas jurídicas são construções emanadas de atos de vontade do homem. Diferentemente de uma explicação causal dos fenômenos naturais, baseada nas leis de ação e reação, a ciência jurídica se norteia em algo construído, imputável, feito por meio de raciocínio lógico para se determinar um fim a que se preza determinada norma (KELSEN, 2009, p. 25).

Com a Renascença na Europa, o direito natural sucumbiu, não cabendo mais ditar as normas de conduta com base apenas em explicações religiosas, concebidas como sendo meras manifestações divinas.

A Renascença trouxe, desse modo, uma crítica ferrenha do real papel do homem na sociedade, pois ele passou a querer ser destaque no mundo e não apenas submisso a forças que ultrapassavam sua órbita individual. Não se podia mais permitir que se tivesse explicação mitológica sobre os fenômenos sociais.

Nesse panorama, segundo Rubem Alves, o positivismo jurídico (as leis criadas pelos homens) veio como elemento mais indicado para estruturar o Direito em um determinado contexto espacial e em uma determinada época. A explicação do direito natural, marcada por abstrações divinas de bem ou mal, cede espaço para a teoria positivista, marcada, pois, pelas características de leis racionais e da fórmula sancionatória para quem as descumpre (ALVES, 2000, p. 86-87).

A explicação subjetiva do naturalismo para tudo o que acontecia na sociedade, como consequência de imposição divina, não acompanhava a necessidade de resposta quanto à evolução e complexidade das relações sociais que se instauravam. Havia necessidade de se criar normas jurídicas para disciplinar de maneira abstrata e objetivamente as relações e conflitos entre os indivíduos, de modo a se restabelecer a normalidade social. Gradativamente o direito abandona a doutrina do direito natural, para incorporar o positivismo jurídico (KELSEN, 2009, p. 25-26).

As normas jurídicas são, portanto, uma construção lógica, com conteúdo que varia de acordo com a época e o local aonde estão inseridas. A norma jurídica tem, sem dúvida, um papel de coordenar e sistematizar o comportamento dos indivíduos, das comunidades, dos 


\section{A NORMA FUNDAMENTAL HIPOTÉTICA DE KELSEN E ANTINOMIA EM RELAÇÃO ÀS CARTAS CONSTITUCIONAIS DEMOCRÁTICAS, COM DESTAQUE À CARTA DEMOCRÁTICA \\ BRASILEIRA DE 1988}

governantes e funcionários do Estado e do Estado perante à comunidade internacional (DINIZ, 2004, p. 26). Eis, portanto, o sentido de racionalidade imposto pelas normas jurídicas.

Kelsen explica que a sanção é outro traço característico das normas. O autor define, em síntese, que o direito como ciência deve ser entendido como uma ordem coativa, um instrumento que regula a ordem social, tendo como característica a imposição de sanção pelos órgãos estatais (efetivamente incumbidos para isso) a todo aquele que descumprir um postulado impositivo. Assim, lança-se o postulado deôntico (dever-ser) no qual todo fato liga-se a uma consequência. Se não cumprir com o que o ordenamento manda, deverá haver uma sanção.

As ciências naturais ou ciências explicativas dos fenômenos naturais possuem o ser como seu objeto de estudo. Já as ciências normativas tratam como objeto o dever ser, ou seja, aquilo que na realidade se espera acontecer. As leis traçadas por essa ciência são normas de conduta, são dadas por meio de preposições jurídicas as quais estabelecem previsão factual e atos de coação. Desse modo, as normas estabelecem que se determinada conduta não for realizada deverá haver uma sanção. Expressam-se na fórmula: Se A deve ser B (COELHO, 1997, p. 35). Faz-se, portanto, análise da conduta humana dirigida por uma vontade.

O Direito, como ramo da ciência normativa, tem como objeto as normas jurídicas positivas, que nada mais são do que as preposições jurídicas mencionadas acima. A ciência jurídica de Kelsen denota um conjunto de normas de conduta, prescritivas, impositivas ou proibitivas, as quais regulam o viver em sociedade.

Sob o prisma da teoria pura, o estudo da norma pode ser feito estática ou dinamicamente, conforme leciona Antonio Celso Mendes:

(A) A estática do direito ou teoria da norma, vai estudá-la contrapondo-se à velha teoria imperativista, conceituando-a como um juízo de dever-ser lógico tipo: Dada a Nãoprestação dever-ser a Sanção. Isto é o que Kelsen denomina norma primária (rechtssatz). Tomada na prática, a norma primária significa: Dado fato temporal deverser a Prestação, que Kelsen denomina norma secundária (rechtsnorm). A teoria pura pretendeu considerar supérflua a norma secundária, com isto procurando solucionar as diversas antinomias que envolviam o direito. Tais são as divergências entre direito natural e positivo, direito subjetivo e objetivo, estado e direito. No entanto, as oscilações de Kelsen enfraqueceram muito a consistência da doutrina, tendo em vistas as críticas que foram procedidas. (B) A dinâmica do direito ou teoria do ordenamento, vai estudálo enquanto mutável, o que implica a sua apreciação enquanto sistema e enquanto competências e formas de sua alteração. Assim, as normas aparecem segundo o grau de sua generalidade, com o que podemos estabelecer uma hierarquia de leis, abrangendo desde as mais específicas até as mais gerais. Igualmente, vemos que há a reger este processo hierárquico, uma dependência ascendente (sentenças-regulamentos-leisconstituição). Isto nos leva à necessidade de pressupor uma norma fundante do sistema, que Kelsen denomina norma fundamental (grundnorm). A teoria da norma fundamental tem sido entendida em dois sentidos: 1) apenas uma exigência hipotética (a priori) com sentido de pressuposto lógico-transcendental e 2) princípio jurídico que fundamenta a legislação de um país (constituição) (MENDES, 1990, p. 89-90). 
O dever ser traduzido em normas jurídicas tem uma dupla acepção: uma acepção subjetiva, que é ligada basicamente na consciência de cada um, naquilo que cada um potencialmente poderia desejar realizar. É a vontade de uma pessoa se sobrepondo à vontade alheia, aniquilando-a, sendo esta uma conduta arbitrária.

Essa conduta humana não tem autorização legal, não é legítima, porque esse dever ser subjetivo não consegue atingir o fim primeiro do conceito de norma para Kelsen, que é de regular a conduta de todos os indivíduos na sociedade. Trata-se, na verdade, de um ato humano avesso a qualquer ordem ou pacificação social.

Já a segunda acepção de dever ser é o que interessa para Kelsen e para o presente estudo. É uma acepção objetiva, segundo a qual as normas de conduta são estruturadas por órgãos legitimamente incumbidos para isso. Tem o condão de serem objetivamente cumpridas por todos indistintamente, impondo sanção a quem não cumprir.

Essa pirâmide normativa é, na verdade, um sucedâneo de dever ser, sendo que uma norma de hierarquia inferior toma como base de fundamento uma norma hierarquicamente superior e assim sucessivamente até chegar ao fundamento primeiro, ou norma fundamental hipotética, que é a norma das normas para Kelsen (grundnorm).

\section{O SISTEMA JURÍDICO E A HIERARQUIA DE NORMAS}

Sistema é o emaranhado de ações que devem se voltar para um fim maior e comum. A constituição é norma mãe desse sistema, é nela que as demais normas buscam seu fim. As normas infraconstitucionais devem servir (buscar a compatibilidade vertical) da norma constitucional. A constituição, segundo Uadi Lammêgo Bulos, é que vai regular toda a estrutura do ordenamento jurídico (BULOS, 2001, p. 38).

O sistema jurídico é, portanto, um emaranhado de normas que se inter-relacionam, buscando um determinado fim comum. Do mesmo modo como o sistema sanguíneo circula em todo o corpo humano, levando nutrientes, realizando a irrigação das células e órgãos; o sistema jurídico orbita por todo o Direito, buscando a pacificação social.

Essa pacificação social só é atingida caso se crie um aparato que transforme o Direito em algo racional, no sentido de que cada norma vai ter uma função para bem desempenhar, do contrário, seria uma total anarquia. A partir daí tem-se noção de ordenamento jurídico.

A hierarquia de normas, concebida por Kelsen, denota sentido semelhante ao exemplo dado. Ao trazer normas com graus de importância diferenciados, aludido mestre quis 


\section{A NORMA FUNDAMENTAL HIPOTÉTICA DE KELSEN E ANTINOMIA EM RELAÇÃO ÀS CARTAS CONSTITUCIONAIS DEMOCRÁTICAS, COM DESTAQUE À CARTA DEMOCRÁTICA \\ BRASILEIRA DE 1988}

demonstrar que só por meio de um sistema escalonado de leis, no qual cada uma delas tem um papel particular e fundamental, pode-se ter um ordenamento jurídico que funcionasse adequadamente.

$\mathrm{O}$ autor colocou relação de dependência entre as normas, de um modo que uma se subordina a outra e todas se subordinam à constituição nacional, conforme já fora mencionado atrás. A constituição nacional é a norma mater desse sistema.

A coesão do ordenamento jurídico só é alcançada quando se tem normas infraconstitucionais que decorram diretamente da constituição, ou que retire o fundamento do texto constitucional. Pensar de forma contrária vai trazer antinomias que causarão instabilidade social, trarão problemas como ineficácia de leis, etc.

A supremacia da constituição, como princípio estruturante do ordenamento jurídico, foi medida que se impôs para garantir a eficácia e funcionalidade de todo o sistema. A supremacia, portanto, resolveu o problema interno, no que toca o fundamento legal das leis infraconstitucionais, guardando correspondência com a compatibilidade vertical, mas e quanto ao fundamento de validade da norma fundamental hipotética de Kelsen? Como se contornará antinomias existentes entre a constituição escrita e o parâmetro da norma fundamental hipotética?

Há antinomia evidente, porque não existe essa mesma compatibilidade vertical quanto à constituição nacional brasileira de 1988 e a concepção de norma fundamental hipotética, porque não há como extrair, conforme se demonstrará, o fundamento de validade daquela constituição do paradigma histórico (regime militar), por não guardarem qualquer correspondência ideológica.

\section{O PRINCÍPIO DA SUPREMACIA DA CONSTITUIÇÃO}

Falar em um sistema que funcione sem antinomias denota a necessidade de haver uma norma que seja a mãe de todas as normas, ou seja, que uma norma tenha prevalência sobre as demais. Essa superioridade é traduzida no princípio da supremacia da constituição.

Gilmar Mendes vai dizer que a supremacia constitucional se divide em duas: há uma supremacia material que está relacionada à matéria, ao conteúdo e ao objeto do estudo. Toda constituição nacional possui a chamada supremacia material. É uma característica comum em todas as constituições (MENDES; BRANCO, 2015, p. 1053). 
A supremacia material são as matérias tratadas na constituição e que se diferenciam das demais normas, justamente por envolver direitos e garantias individuais, estrutura do Estado e a separação (e estabelecimento de competências) dos poderes Executivo, Legislativo e Judiciário. Na visão norte-americana, a supremacia material da constituição vem da ideia de estabelecer as regras do jogo político.

Será a constituição que vai dizer quem manda, como manda e até onde esses poderes podem mandar. Como aquela norma estabelece as regras do jogo político ela deve estar em nível superior daqueles que participam do jogo em si, porque, do contrário, nada impediria que os poderes violassem referidas regras. Assim, a supremacia material da constituição é decorrência lógica daquele sistema adotado.

Só que esta supremacia material só tem relevância sociológica. Não tem relevância no plano jurídico (segundo Kelsen). A supremacia relevante juridicamente é a supremacia formal da constituição, ou seja, o fato de estar a norma constitucional acima das demais. A consequência direta desse sistema é justamente a questão da validade das normas, o seu plano de eficácia de leis (assuntos que serão tratados mais adiante).

Há, portanto, ao lado da supremacia material, a supremacia formal que está relacionada à forma, à posição ocupada no sistema jurídico, etc. Só se pode falar em supremacia formal se a constituição decorrer de sua rigidez.

Esse princípio diz, portanto, que a constituição nacional é norma suprema e, portanto, os atos dos poderes públicos só serão válidos se estiverem de acordo com a constituição. No plano dogmático positivo, a consequência da supremacia constitucional é que ela vai determinar tanto a forma de elaboração de leis (por exemplo), como o conteúdo dessas leis e atos normativos. As leis e atos dos poderes públicos só serão válidos a partir do momento que obedecerem à forma e conteúdo da constituição.

O princípio da supremacia da constituição, bem como ser o ordenamento jurídico um todo hierárquico, conseguem evitar que antinomias se instaurem, que conflitos de leis se operem, expurgando do sistema tudo o que não condiz com a constituição nacional, ou menos por aquilo que ela prega. 


\section{A NORMA FUNDAMENTAL HIPOTÉTICA DE KELSEN E ANTINOMIA EM RELAÇÃO ÀS CARTAS CONSTITUCIONAIS DEMOCRÁTICAS, COM DESTAQUE À CARTA DEMOCRÁTICA \\ BRASILEIRA DE 1988}

\section{A NORMA FUNDAMENTAL HIPOTÉTICA E A CONCEPÇÃO DE CONSTITUIÇÃO POR KELSEN}

Antes de adentrar no conceito de norma fundamental e de constituição dado por Kelsen, é imperioso entender o fenômeno do constitucionalismo ${ }^{l}$ que se inseriu no mundo, quais as experiências constitucionais e de que forma esse fenômeno foi importante para os Estados democráticos de direito que se têm na atualidade.

Em um sentido amplo o constitucionalismo está ligado à existência de uma constituição. Aonde existir uma constituição vai existir um constitucionalismo. Todo Estado moderno tem uma constituição ou uma norma de organização primordial, mesmo que não seja escrita. Essa é a ideia que foi concebida do constitucionalismo quando ele surgiu.

E várias foram as experiências constitucionais ocorridas na Europa e América do Norte antes de se chegar ao conceito atual de constituição. $O$ constitucionalismo veio como contraponto ao chamado absolutismo. A história do constitucionalismo é a busca do homem político ao governo limitado, contra o arbítrio do poder soberano do rei. Os momentos do constitucionalismo, na história, podem ser divididos em dois: o constitucionalismo antigo e o constitucionalismo clássico.

No constitucionalismo antigo ocorreram quatro experiências importantes, qual seja, a experiência do Estado Hebreu, da Grécia Antiga, de Roma e da Inglaterra.

A experiência do Estado Hebreu é associada com o Estado teocrático. O histórico do constitucionalismo, de uma forma geral, sempre vem ligado à garantia de direitos, à separação de poderes, e ao governo limitado. Entre os hebreus, a ideia que prevalecia era de um governo limitado por meio de dogmas consagrados na Bíblia. É por isso que se fala em Estado teocrático (LOEWESTEIN, 1970, p. 154-155).

Foi na Grécia Antiga onde ocorreu a mais avançada forma de governo da história antiga. Por meio de uma democracia constitucional na cidade-estado de Atenas, no governo de Sólon, havia a participação direta do povo nas decisões políticas do Estado (ARAÚJO, 2013, p. 191).

\footnotetext{
${ }^{1}$ Para este artigo, o termo "constitucionalismo será utilizado na acepção da imposição de que há cartas constitucionais escritas, que englobem as regras que vão delinear a estrutura do Estado, que definem as diversas competências e disciplinem os limites dos Poderes constituídos, bem como trazendo rol de direitos e garantias fundamentais, conceito este também observado por André Ramos Tavares (TAVARES, 2002, p. 1).
} 
A experiência de Roma é marcada pela ideia de liberdade. Nenhum outro Direito concebeu a ideia de liberdade de uma forma tão digna e tão correta quanto o direito romano (IHERING, 2000, p. 33).

$\mathrm{Na}$ Inglaterra aconteceu a experiência chamada de rule of Law. A experiência constitucional inglesa lançou duas ideias fundamentais: a do governo limitado; e a de igualdade dos cidadãos ingleses perante a lei. Na Inglaterra não existe uma Constituição escrita, todavia, desde aquela época existiam documentos de grande valor constitucional, como, por exemplo, a Magna Carta de 1215, o Bill of Rights, o Petition of Rights, o Act of habeas corpus, são todos documentos escritos que têm um grande valor constitucional (FERREIRA FILHO, 1999, p. 04$05)$.

Luís Fernando Coelho esclarece que, embora sejam os principais, outros modelos também ocorreram na antiguidade, bem como funcionaram como pressupostos teóricos utilizados para o advento do constitucionalismo moderno, tais como foram a "Lei das XII Tábuas” de 453 a.C. (COELHO, 2006, p. 30)

No Constitucionalismo clássico (ou também chamado por alguns de constitucionalismo liberal) há duas experiência fundamentais, quais sejam, a experiência do constitucionalismo norte-americano de 1787 e do constitucionalismo francês de 1791.

Nos Estados Unidos foi feita a primeira constituição escrita conhecida no mundo, chamada de Declaração de Direitos do Estado de Virgínia de 1776. Logo depois dessa Declaração, foram surgindo documentos constitucionais até surgir a constituição norteamericana que está em vigor até a data de hoje (DRIVER, 2006, p. 39-48).

Quanto a segunda experiência (francesa) foi aonde surgiu a primeira constituição escrita na Europa, criada em 1791, embora a primeira constituição escrita moderna, conforme dito, apareceu primeiro nos Estados Unidos (COELHO, 2006, p. 30-31).

E, após a Primeira Guerra Mundial, foi repensado o modelo clássico de constitucionalismo, de cunho liberal, porque não atendia às demandas sociais. Era um modelo de constitucionalismo extremamente burguês, trazendo consigo uma série de desigualdades, as quais só foram amenizadas com o surgimento do chamado constitucionalismo social. Foi nesse contexto que apareceram as diversas concepções do fenômeno constitucional.

O século XX foi marcado por sangrentas batalhas. As duas Guerras Mundiais demonstraram que o positivo estrito era incapaz de trazer a paz social, uma vez que não foi capaz de impedir que constituições pregassem segregações raciais, discriminações gratuitas, o ódio entre povos. 


\section{A NORMA FUNDAMENTAL HIPOTÉTICA DE KELSEN E ANTINOMIA EM RELAÇÃO ÀS CARTAS CONSTITUCIONAIS DEMOCRÁTICAS, COM DESTAQUE À CARTA DEMOCRÁTICA \\ BRASILEIRA DE 1988}

A constituição nazista, do ponto de vista da teoria kelseniana, era perfeitamente válida, porque decorreu diretamente de uma revolução, de uma ruptura do antigo regime. A norma fundamental hipotética foi justamente a tomada do partido nazista ao poder em 1934 (BOBBIO; MATTEUCCI; PASQUINO, 1998, p. 811).

Diante esses maus exemplos na história mundial é que foi imperiosa a necessidade de se repensar todo o sistema legal, a sua estrutura, criar limites, estabelecer prioridades a serem dadas nas cartas constitucionais. A liberdade de bem estabelecer as normas cedeu espaço à dignidade do homem, a sua condição de ser dotado de direitos e que nem mesmo o Estado poderia supri-los. Foi também repensado o significado de constituição nacional, sobre a ótica das realidades as quais aquela se inseriu.

E, a partir daí, surgiram vários teóricos para conceituar o fenômeno constitucional, seu núcleo intangível e o conteúdo normativo a que se deveria prestar as Cartas constitucionais que surgiram após o advento dos Estados modernos.

A concepção de constituição que é dada por Ferdinand Lassalle, conhecida como concepção sociológica (LASSALLE, 2000, p. 10-11), dispõem que, dentro de um Estado, há duas constituições: uma que é real ou efetiva; outra constituição que é escrita.

A constituição escrita é a síntese daquilo que se tem assegurado no texto constitucional. São basicamente as normas jurídicas sistematizadas em um codex. Já a constituição real ou efetiva é a soma dos fatores reais de poder que regem determinada nação. Um exemplo que Lassalle dá de sua época (século XIX quando escreveu seu livro A essência da constituição) é que aonde há banqueiros e aristocracia serão eles quem vão criar a constituição, ou seja, a constituição representa ou protege o poder econômico dessa parcela da população (LASSALE, 2000, p. 17-18).

Para ele, a constituição escrita que não representa os fatores reais de poder torna-se irrelevante e carente de força normativa, não passando de mera "folha de papel". O que realmente importa é a constituição real ou efetiva (LASSALLE, 2000, p. 33).

Já há outro pensador que adota uma concepção política de constituição. Carl Schmitt é quem defende essa ideia no seu livro "o guardião da Constituição" em 1931. Schmitt ferrenhamente se contrapõe ao pensamento de Kelsen, adotando um conceito chamado de decisionista de constituição (SCHMITT, 2007, p. 67).

Por esse conceito, Carl Schmitt faz distinção entre o que seria constituição propriamente dita e o que chama de leis constitucionais. Constituição propriamente dita é aquela que decorre de uma decisão política fundamental. É conceito decisionista, porque para 
ele só é constituição aquilo que decorre de uma decisão política fundamental, ou seja, qualquer outra matéria que não envolva direitos e garantias individuais, estrutura do Estado e organização de poderes não é constituição, mas apenas integra o texto constitucional (ou, para ele, meras leis constitucionais) (SCHMITT, 2007, p. 67).

Já para a concepção jurídica de constituição de Hans Kelsen, todas as leis devem buscar seu fundamento de validade na constituição nacional, que é uma norma superior de hierarquia que vincula a produção legal infraconstitucional. Para o autor, havia dois conceitos distintos dentro de sua concepção de constituição:

O primeiro deles é o de constituição em sentido lógico-jurídico, o que seria a chamada norma fundamental hipotética. É fundamental, porque ela serve de fundamento para a constituição em sentido jurídico-positivo. Hipotética, porque não é posta pelo Estado, mas apenas pressuposta. É apenas uma hipótese, ou seja, não se tem escrita a norma fundamental hipotética em lugar algum. Seria apenas uma pressuposição da qual se deveria partir para buscar o sentido de constituição jurídico-positivo.

A partir de Kelsen entende-se que a lei infraconstitucional retira seu fundamento de validade da constituição nacional, mas, todavia, surge inexoravelmente o seguinte questionamento: de onde o constituinte nacional originário retirou os fundamentos ou princípios que vieram a compor a norma constitucional de 1988 ?

A resposta é que não há acima da constituição nacional qualquer norma jurídica em sentido positivo, mas existe, todavia, uma norma superior e hipotética, sem a qual a constituição escrita não teria fundamento.

Desse modo, Kelsen entende como constituição em sentido jurídico-positivo a constituição palpável, o sentido que se é aplicado costumeiramente, como o é a Constituição da República Federativa do Brasil de 1988. É aquela constituição feita pelo legislador positivo. Constituição posta pelo Estado (KELSEN, 2009, p. 25-26).

A norma fundamental hipotética, nesse panorama, foi uma forma de Kelsen contornar seu conceito de constituição, de seu purismo doutrinário, fechando a pirâmide normativa, na qual uma lei vai ser fundamento de validade de outra e todas elas de uma norma superior (que não é posta, mas apenas suposta ou pressuposta, pois, do contrário, deveria se regredir às normas dos ancestrais da caverna para se chegar a primeira norma de conduta estabelecida pelo homem).

Diferentemente de Lassalle e Schmitt que acabam por entender o fenômeno constitucional por uma visão sociológica ou política, Kelsen, explica Fábio Ulhoa Coelho, teve 


\section{A NORMA FUNDAMENTAL HIPOTÉTICA DE KELSEN E ANTINOMIA EM RELAÇÃO ÀS CARTAS CONSTITUCIONAIS DEMOCRÁTICAS, COM DESTAQUE À CARTA DEMOCRÁTICA \\ BRASILEIRA DE 1988}

que aprofundar sua teoria para explicar de outra forma que não envolvesse o homem e suas relações sociais. O purismo de sua teoria é basicamente encontrar o fundamento para a constituição nacional dentro de um sistema hierárquico de lei (e daí que decorre a crítica lançada neste artigo) (COELHO, 1997, p. 31).

A revolução ${ }^{2}$, assim como já foi dito, vai vir como elemento desintegrador de toda uma normatividade anterior, para se ter uma nova ordem instaurada. É como base nessa ruptura abrupta que se baseará, ou mesmo, será decorrência toda uma normatividade posterior.

Conforme já mencionado, no Brasil a norma fundamental hipotética que se tem notícia atualmente foi o Ato Institucional número 05. Referido ato proveio de um golpe militar, instaurando-se posteriormente uma ditadura, suprimindo direitos individuais, etc.

Maria José de Rezende destaca, sobre a necessidade, para a manutenção do golpe de Estado, do estabelecimento de um "regime de terror", sob a falácia da manutenção da ordem institucional, já que, segundo a autora, "os condutores e sustentadores da ditatura militar tentavam arrancar a natureza do próprio poder os meios de justificá-lo. Portanto, a lógica da legitimidade coercitiva supunha que o regime vigente era o gerador e o mantenedor do consentimento e não a coletividade social (REZENDE, 2013, p. 91).

A teoria de Kelsen representa uma possível antinomia ao como condicionante da norma fundamental hipotética a existência de ruptura abrupta da ordem jurídica anteriormente vigente, ou seja, somente por meio de revolução é que se nasceria nova norma fundamental hipotética.

Juristas tais como Tércio Sampaio Ferraz Júnior e Noberto Bobbio estudam o tema antinomia, dizendo que seria uma lei incompatível com outra, seja de forma parcial, seja de forma total. Quando um texto vem de encontro com outro dispositivo legal ter-se-á a chamada antinomia (FERRAZ JÚNIOR, 1994, p. 122).

Bobbio, com semelhança do que pensa Kelsen, também afirma que a norma jurídica continuará válida até ser revogada por outra, não importando que seja incompatível com o texto

\footnotetext{
${ }^{2}$ Revolução para fins do presente artigo é compreendida, nos termos de Nicola Abbagnano, como sendo "violenta e rápida destruição de um regime político, ou mudança radical de qualquer situação cultural”. O autor destaca que, na história, alguns exemplos dão maior precisão ao conceito, como o termo de "revolução política" diretamente relacionado com "[...] que teve início no sec. XVIII, revoluções propriamente ditas foram a inglesa, a americana, a francesa e a russa, mas às vezes também são chamadas de revolução transformações políticas que tiveram menor importância na história geral do mundo, apesar de serem marcos fundamentais na história de determinado país" (ABBAGNANO, 2007, p. 859). Assim, tomar-se-á com base o conceito de Abbagnano, no qual o termo revolução sempre vem acompanhado de rupturas abruptas na ordem pré-estabelecida, pressupondo grandes modificações nas estruturais estatais e de governo, experimentadas no país aonde acontece eventos revolucionários.
} 
constitucional (BOBBIO, 1999, p. 34). Há, portanto, duas formas de antinomia. Há a antinomia real e a antinomia aparente.

Flávio Tartuce diz que na antinomia real nenhum dos critérios estabelecidos pelo sistema, ou seja, a) critério cronológico: norma posterior prevalece sobre norma anterior; b)critério da especialidade: norma especial prevalece sobre norma geral; c)critério hierárquico: norma superior prevalece sobre norma inferior é possível de contornar o problema do conflito de leis. Já a antinomia aparente, segundo o mesmo autor, pode ser resolvida utilizando-se de umas das técnicas acima expostas, quer pelo uso da norma hierarquicamente superior, quer utilizando os critérios da especialidade ou mesmo cronológico (TARTUCE, 2005).

A antinomia reside no fato que não se pode mais aceitar a revolução abruta, ou violenta, com pressuposto para inaugurar nova norma fundamental hipotética, a partir do estabelecimento das Cartas democráticas.

Desse modo, não há como concordar com a teoria de Kelsen, pelo menos quando se trata da experiência brasileira, porque o atual sistema jurídico não retira sua base e fundamento do Ato institucional número 05, conforme registra Fábio Ulhoa Coelho, ao escrever comentários sobre a obra de Kelsen:

O Ato institucional número 05 é ainda a primeira constituição histórica brasileira, porque a ordem jurídica iniciada com a sua edição ainda não foi substituída. Todas as normas hoje vigentes se ligam, mediatamente a este ato de exceção, fonte última de sua validade. A carta de 1988 tem seu fundamento na emenda à carta de 1967 e esta foi totalmente reeditada em 1969, com base naquele ato excepcional. A norma hipotética fundamental pressuposta pela ciência do direito brasileira, portanto, não poderia ser outra senão a prescrição de obediência ao editor do Ato Institucional número 05 (COELHO, 1997, p. 31-32).

A constituição nacional de 1988 representou o oposto daquilo que o AI 05 pregava (tomando como base o marco histórico do Golpe Militar de 1964, como sendo a última ruptura abrupta da ordem ou normalidade jurídica vigente). Ela veio para dizer um basta, veio para dizer um não ao autoritarismo, reascendeu a chama democrática e de cidadania que estava há anos apagada na consciência do povo brasileiro.

A concepção purista, muito embora tenha sido adotada no Brasil - justamente porque lança uma teoria quase que irrefutável, teoria que vem explicar o ordenamento jurídico como um todo complexo e hierarquicamente estruturado - traz dificuldades quanto à questão da eficácia e validade das normas que surgiram após a constituição nacional de 1988.

As leis não podem ser construídas ignorando totalmente o que os princípios constitucionais, o direito internacional, o senso comum de justiça pregam, por deixarem de ser 


\section{A NORMA FUNDAMENTAL HIPOTÉTICA DE KELSEN E ANTINOMIA EM RELAÇÃO ÀS CARTAS CONSTITUCIONAIS DEMOCRÁTICAS, COM DESTAQUE À CARTA DEMOCRÁTICA \\ BRASILEIRA DE 1988}

válidas no aspecto substancial. O fundamento de que formalmente cumpriu os requisitos de elaboração de uma lei, ou mesmo que está em consonância com a norma fundamental hipotética (para o caso do constituinte) vai ceder espaço ao campo da avaliação de critérios de justiça de referida norma (HESSE, 1991, p. 15-20).

Há mais um problema da doutrina de Kelsen a ser aplicada hoje em dia, pois não é possível ignorar o fenômeno do Estado democrático de direito. Não se pode mais conceber normas jurídicas que gravitam em órbita diferente das normas constitucionais; ou estas gravitando sobre uma órbita de norma hipotética fundamental totalmente incoerente com o sistema legal, por carecerem de eficácia.

Normas que são contrárias à constituição (inválidas) devem ser ceifadas do ordenamento jurídico, sob pena de comprometerem a credibilidade do sistema, ou a segurança jurídica.

\section{O PROBLEMA DA ANTINOMIA DA CONSTITUIÇÃO NACIONAL BRASILEIRA EM RELAÇÃO À NORMA FUNDAMENTAL HIPOTÉTICA PELA CONCEPÇÃO DE KELSEN}

O purismo de Kelsen, concebido no início do século $\mathrm{XX}$, deve receber algumas adaptações, mais especificamente pelo fato de que a realidade constitucional, atrelada ao estado democrático de direito e a prevalência dos princípios constitucionais não comportam mais uma explicação de norma fundamental hipotética como foi concebida.

Lei infraconstitucional que não seja compatível com as normas constitucionais deve ser retirada do ordenamento jurídico, e não mais ser considerada como válida da maneira que queria Kelsen, só saindo do ordenamento jurídico quando outra lei a revogasse.

Do mesmo modo que a norma fundamental hipotética deve ser hoje concebida não mais como o fruto de uma simples revolução, mas sim como sucedâneo de fatores e direitos considerados ao longo dos anos pela humanidade (da herança histórica de direitos individuais alcançados), da evolução do constitucionalismo no mundo, etc. O poder constituinte originário (que vai se basear na norma fundamental hipotética para escrever nova constituição) não é ilimitado, vai sofrer algumas limitações que o estado atual da sociedade civilizada impôs.

Jorge Miranda afirma que o poder constituinte originário deve obedecer aos chamados limites transcendentes que são derivados de imperativos do direito natural, de valores éticos (KANT, 1974, p. 220), ou da consciência jurídica coletiva. Ex. direitos fundamentais que estão 
ligados diretamente à Dignidade da Pessoa Humana não poderão ser suprimidos, pois, do contrário, a constituição nacional não seria legítima (MIRANDA, 2003).

Ligado diretamente a essa ideia está o princípio da proibição de retrocesso, pois se a nova constituição não consagra direitos que a sociedade já conquistou, haveria um retrocesso social (BARROSO, 2001, p. 158).

Põem-se em xeque a norma fundamental hipotética neste aspecto, porque ao impor que seja esta exclusivamente fruto de uma revolução, de rupturas abrutas que pressupõem, para a implementação do golpe, a utilização de poderes despóticos ou tiranos (assim como foi no Brasil o Golpe Militar de 1964 e a sua formalização jurídica de aludido golpe, ocorrida por meio do instrumento denominado de "AI 05") vai trazer um problema na própria hierarquia de leis e no sistema jurídico como um todo.

Isso porque, como a leis infraconstitucionais decorrem da constituição nacional e esta de sua norma fundamental hipotética, não é possível que esta lei superior pregue poderes ditatoriais enquanto a constituição nacional seja o extremo oposto, garantindo inúmeros direitos civis e políticos, retirando ao máximo o poderio militar, etc. Há uma evidente antinomia real entre lei (constituição nacional) e seu fundamento de validade (norma fundamental hipotética).

Entende-se, dessa forma, que os princípios constitucionais, os postulados éticos, o senso coletivo jurídico de justiça devem prevalecer, para resolver essa antinomia, ou seja, devese afastar o conceito da norma fundamental hipotética, da forma concebida por Kelsen, que não condiz com a realidade constitucional, como aconteceu no caso do Brasil.

Nesse ponto, conclui-se que os princípios da dignidade da pessoa humana, do Estado Democrático de Direito, da proibição do retrocesso devem prevalecem sobre qualquer outro fundamento de validade que se inspirou o texto constitucional. Pensar de forma contrária poderia dar cabo a normas escritas que carecem de validade, ante a antinomia demonstrada (norma fundamental hipotética incompatível com a inspiração do texto constitucional).

A dignidade da pessoa humana é considerada como valor constitucional supremo. Ao ser consagrada, por exemplo, como fundamento da República Federativa do Brasil (art. $1^{\circ}$, III, da CRFB/1988), entende-se de uma forma geral como sendo o núcleo axiológico da constituição nacional.

Desse modo, a estrutura do ordenamento jurídico como foi concebido por Kelsen, mormente quanto à norma fundamental hipotética, e da estrutura normativa de forma piramidal, não pode mais ser compatibilizada com a existência do pressuposto que é a ruptura abrupta ou revolução violenta que, no Brasil, aconteceu por último com o Golpe de 1964 e o 


\section{A NORMA FUNDAMENTAL HIPOTÉTICA DE KELSEN E ANTINOMIA EM RELAÇÃO ÀS CARTAS CONSTITUCIONAIS DEMOCRÁTICAS, COM DESTAQUE À CARTA DEMOCRÁTICA \\ BRASILEIRA DE 1988}

estabelecimento do Ato Institucional n. 05. Hoje, como demonstrado, as transições democráticas se deram de maneira suave, por meio de consensos da maioria dos segmentos da sociedade.

O fruto do constitucionalismo contemporâneo é o diálogo, a valorização da pessoa e a pluralidade de ideologias que se devem compatibilizar de maneira pacífica, dentro das constituições democráticas.

A volta dos valores éticos, da busca da fraternidade dos povos, da abolição de regimes de exceção tudo deve sopesar sobre qualquer outro fundamento de validade da constituição nacional, bem como da normatividade como um todo. Não basta estar a lei de acordo com os requisitos formais de sua elaboração, mas sim que o fim buscado pela norma seja adequado àquilo que se propõe no estado democrático de direito (valorização da pessoa humana).

Pensar de forma diferente seria retroceder na conquista dos direitos, seria deixar de lado a dignidade da pessoa humana tudo para se trabalhar com um conceito puro de Direito, mas que não mais é aceito pela comunidade internacional.

O Direito e sociedade são elementos indissociáveis, porque aquele decorre desta. Não existe Direito aonde não há pessoas humanas, com toda a complexidade de relações sociais e conflitos que somente aquele pode solucionar, trazendo a paz social e a possibilidade de vida em grupo. São conceitos intimamente ligados, um moldando o outro, não podendo ser algo individualizado, sem relação direta, porque, do contrário, faltaria legitimidade por parte do Direito.

A norma fundamental hipotética, portanto, deve contemplar todos os direitos consagrados até hoje, não podendo ser fruto de apenas um grupo de revolucionários que tomaram o poder e querem mudar o regime violentamente. Carecerá de legitimidade todo o ordenamento de leis que dela decorrer, sem que seja previsto direitos e garantias individuais, a dignidade da pessoa humana, princípio da igualdade e tantos mais que forem necessários para adequar o positivismo à real necessidade de ética e moral.

\section{CONCLUSÕES}

O Direito, por ser mutável, deve ter suas teorias adaptadas para alcançar o objetivo de corresponder com a realidade em que são postas. De nada adiantaria um purismo impecável de uma norma se a sociedade não a cumpre. Seria criar normas com o intuito de atender alguma 
necessidade formal de criar leis, mas sem que houvesse o respaldo ou aceitação social e a legitimidade.

Nesse ponto, ao contrário de Kelsen que não aceita o Direito como sendo um fenômeno social, demonstrou-se que não é mais possível retirar totalmente os elementos sociais, históricos, a evolução de conceitos apenas para tentar transformar o Direito em algo matemático, ou quase em uma ciência exata.

De nada adiantaria haver uma carta política imutável, mas que não fosse capaz de condizer com a realidade. O fenômeno constitucional, com destaque ao que foi produzido com o advento do Estado moderno, vem sofrendo inúmeras alterações, acolhendo - basicamente uma série de direitos individuais e sociais, em detrimento ao poderio estatal.

Assim, conclui-se no trabalho que, o atual estágio em que se encontra o homem, não possibilita pensar que uma constituição nacional seja simplesmente o fruto da norma fundamental hipotética (que decorra de uma revolução) que acabe com toda uma série de direitos consagrados e aceitos na comunidade internacional.

Se a constituição nacional escrita não corresponder ao seu fundamento de validade primeiro, qual seja, a norma fundamental hipotética, deve-se falar então que há uma antinomia real no sistema hierarquizado de leis que só será resolvida com a concretização ou prevalência dos princípios mais importantes para o homem (a dignidade da pessoa humana, a igualdade e liberdade).

Finaliza-se ressaltando que a literatura já publicada sobre o tema é escassa, havendo poucos doutrinadores que se arriscam a defender a posição aqui levantada. Assim, diante essa limitação e pelas conclusões aqui apresentadas é de se considerar satisfatório esse estudo, por trazer novas opiniões sobre o assunto.

Diante disso, espera-se que a contribuição trazida por esse estudo venha a enriquecer a Ciência jurídica, tendo em vista que o Direito não é estático, mas sim sempre deve acompanhar os avanços da sociedade, pois, do contrário, petrifica-se e se torna letra morta. 


\section{A NORMA FUNDAMENTAL HIPOTÉTICA DE KELSEN E ANTINOMIA EM RELAÇÃO ÀS CARTAS CONSTITUCIONAIS DEMOCRÁTICAS, COM DESTAQUE À CARTA DEMOCRÁTICA \\ BRASILEIRA DE 1988}

\section{REFERÊNCIAS BIBLIOGRÁFICAS}

ABBAGNANO, Nicola. Dicionário de filosofia. Tradução da $1^{\mathrm{a}}$ edição brasileira por Alfredo Bossi, revisão da tradução e tradução dos novos textos Ivone Castilho Benedetti. 5. Ed. São Paulo: Martins Fontes, 2007.

ALVES, Rubem. Filosofia da Ciência: Introdução ao Jogo e a Suas Regras. São Paulo: Loyola, 2000.

ARAÚJO, Aloízio Gaonzaga de Andrade. O Direito e o Estado como Estruturas e Sistemas: um contributo à teoria geral do Direito e do Estado. Belo Horizonte: Ubirajara Coelho Neto, 2013.

BARROSO, Luís Roberto. O direito constitucional e a efetividade de suas normas. 5. ed. Rio de Janeiro: Renovar, 2001.

BOBBIO, Norberto. Teoria do Ordenamento Jurídico. 10. ed. Brasília: UnB, 1999.

BOBBIO; MATTEUCCI; PASQUINO. Dicionário de Política, Tradução Carmen C. Varriale, Gaetano Lo Mônaco, João Ferreira, Luís Guerreiro Pinto Cacais e Renzo Dini. 11. ed. Brasília: UnB, 1998.

BRASIL. Constituição (1988). Constituição da República Federativa do Brasil de 1988 n $^{\circ}$ CF/88, de 05 de outubro de 1988. Constituição Federal. Brasília, Disponível em: <http://www.planalto.gov.br/ccivil_03/constituicao/constituicaocompilado.htm>. Acesso em: 21 set. 2016.

BULOS, Uadi Lammêgo. Constituição Federal Anotada. 3. ed. São Paulo: Saraiva, 2001.

COELHO, Fábio Ulhoa. Para Entender Kelsen. 2. ed. São Paulo: Max Limonad, 1997.

COELHO, Luiz Fernando. Direito constitucional e filosofia da constituição. Curitiba: Juruá, 2006.

COELHO, Luiz Fernando. Teoria crítica do direito. 3. ed. rev., atual. e ampl. Belo Horizonte: Del Rey, 2003.

COSTA, Judith Martins (Org.). A reconstrução do direito privado. São Paulo: Revista dos Tribunais, 2002.

DINIZ, Maria Helena. Curso de direito civil: teoria geral do direito civil, v. 1. 21. ed. São Paulo: Saraiva, 2004.

DRIVER, Stephanie Schwartz. A Declaração de Independência dos Estados Unidos. Tradução de Mariluce Pessoa. Rio de Janeiro: Jorge Zahar Ed., 2006.

Rev. Brasileira de Teoria Constitucional | e-ISSN: 2525-961X | Brasília | v. 3 | n. 1 | p. 56- 78 | Jan/Jun. 2017 
FERRAZ JÚNIOR, Tércio Sampaio. Introdução ao Estudo do Direito. 2. ed. São Paulo: Atlas, 1994.

FERREIRA FILHO, Manoel Gonçalves. Curso de Direito constitucional. São Paulo: Saraiva, 1999.

HESSE, Konrad. A força normativa da constituição. Tradução de Gilmar F. Mendes. Porto Alegre: Sergio Antonio Fabris Editor, 1991.

IHERING, Rudolf Von. A Luta pelo Direito. São Paulo: Editora Martin Claret Ltda, 2000.

KANT, Immanuel. Crítica da Razão Pura. São Paulo: Abril Cultural, 1974.

KELSEN, Hans. Teoría Pura del Derecho. 4. ed. Buenos Aires: Eudeba, 2009.

LASSALLE, Ferdinand. A essência da Constituição. 5. ed. Rio de Janeiro: Lumen Juris, 2000.

LOEWESTEIN, Karl. Teoría de la constitución. 2. ed. Barcelona: Ariel, 1970.

MACHADO S., Hugo de Brito. Fundamentos do Direito. São Paulo: Atlas, 2010.

MENDES, Antonio Celso. Direito, ciência, filosofia e política. 3. ed. Curitiba: Educa, 1990.

MENDES, Gilmar Ferreira. BRANCO, Paulo Gustavo Gonet. Curso de Direito Constitucional. 9. ed. Rio de Janeiro: Saraiva, 2015.

MIRANDA, Jorge. Teoria do Estado e da Constituiçãa. Rio de Janeiro: Forense, 2003.

REZENDE, Maria José de. A ditadura militar no Brasil: repressão e pretensão de legitimidade: 1964-1984. Livro Eletrônico. Londrina: Eduel, 2013.

SCHMITT, Carl. O guardião da Constituição. Tradução de Geraldo de Carvalho; coordenação e supervisão Luiz Moreira. Belo Horizonte: Del Rey, 2007.

SIQUEIRA, Dirceu Pereira; FERRARI, Caroline Clariano. O direito à informação como direito fundamental ao estado democrático. Revista Direitos Sociais e Políticas Públicas Unifafibe. v. 4, n. 2, 2016.

; OLIVEIRA, Flávio Luis (Orgs.). Constitucionalismo, democracia, procedimento e substância. Birigui: Boreal, 2013.

; RUIZ, Ivan Aparecido (Orgs.). Acesso à justiça e os direitos da personalidade. Birigui: Boreal, 2015.

TARTUCE, Flávio. Breve estudo das antinomias ou lacunas de conflito. Jus Navigandi, Teresina, ano 10, n. 879, 29 nov. 2005. Disponível em: <http://jus.uol.com.br/revista/texto/7585>. Acesso em: 6 dez. 2010. 
TAVARES, André Ramos. Curso de Direito Constitucional. 1. ed. São Paulo: Saraiva, 2002.

VENOSA, Sílvio de Salvo. Introdução ao estudo do direito: primeiras linhas. 2. ed. 6. reimp. São Paulo: Atlas, 2009. 